\title{
Noninvasive ventilation practice patterns for acute respiratory failure in Canadian tertiary care centres: A descriptive analysis
}

\author{
Geneviève C Digby $M D^{1}$, Sean $P$ Keenan $M^{2}{ }^{2}$, Christopher M Parker MD MSc ${ }^{1}$, Tasnim Sinuff $M D^{3}$, \\ Karen E Burns MD MSc${ }^{4}$, Sangeeta Mehta $\mathrm{MD}^{5}$, Juan J Ronco MD', Demetrios J Kutsogiannis MD MHS , \\ Louise Rose RN MN PhD ${ }^{3,8}$, Najib T Ayas MD MPH ${ }^{9}$, Luc R Berthiaume MD MSc ${ }^{10}$, \\ Christine L D'Arsigny $M D^{1}$, Daniel E Stollery $M D^{11}$, John Muscedere MD ${ }^{1}$
}

GC Digby, SP Keenan, CM Parker, et al. Noninvasive ventilation practice patterns for acute respiratory failure in Canadian tertiary care centres: A descriptive analysis. Can Respir J 2015;22(6):331-340.

BACKGROUND: The extent of noninvasive ventilation (NIV) use for patients with acute respiratory failure in Canadian hospitals, indications for use and associated outcomes are unknown.

OBJECTIVE: To describe NIV practice variation in the acute setting. METHODS: A prospective observational study involving 11 Canadian tertiary care centres was performed. Data regarding NIV indication, mode and outcomes were collected for all adults ( $>16$ years of age) treated with NIV for acute respiratory failure during a four-week period (between February and August 2011). Logistic regression with site as a random effect was used to examine the association between preselected predictors and mortality or intubation.

RESULTS: A total of 330 patients (mean [ \pm SD] $30 \pm 12$ per centre) were included. The most common indications for NIV initiation were pulmonary edema (104 [31.5\%]) and chronic obstructive pulmonary disease (99 [30.0\%]). Significant differences in indications for NIV use across sites, specialty of ordering physician and location of NIV initiation were noted. Although intubation rates were not statistically different among sites (range $10.3 \%$ to $45.4 \%$ ), mortality varied significantly (range $6.7 \%$ to $54.5 \% ; \mathrm{P}=0.006$ ). In multivariate analysis, the most significant independent predictor of avoiding intubation was do-not-resuscitate status (OR $0.11[95 \%$ CI 0.03 to 0.37$])$.

CONCLUSION: Significant variability existed in NIV use and associated outcomes among Canadian tertiary care centres. Assignment of do-notresuscitate status prevented intubation.

Key Words: Acute respiratory failure; Noninvasive ventilation; Practice variation

In the past two decades, there has been increased interest in the use of noninvasive ventilation (NIV) as a treatment for acute respiratory failure (1-3). NIV can provide ventilatory support with similar physiological benefits as invasive mechanical ventilation, including reduced work of breathing and improved gas exchange (4). NIV has advantages including the need for less sedation, reduced risk for ventilator-associated pneumonia, and shorter durations of ventilation and intensive care unit (ICU) stay (5). Consequently, the use of NIV
Les modalités de ventilation non invasive pour l'insuffisance respiratoire aiguë dans les centres canadiens de soins tertiaires : une analyse descriptive

HISTORIQUE : On ne connaît pas la portée de l'utilisation de la ventilation non invasive (VNI) chez les patients ayant une insuffisance pulmonaire aiguë dans les hôpitaux canadiens, ni les indications et les résultats cliniques s'y rapportant.

OBJECTIF : Décrire les variations de pratique liées à la VNI en soins aigus. MÉTHODOLOGIE : Les chercheurs ont effectué une étude d'observation prospective dans 11 centres canadiens de soins tertiaires. Ils ont colligé les données relatives aux indications, aux modalités et aux résultats cliniques liés à la VNI pour tous les adultes de plus de 16 ans traités par VNI en raison d'une insuffisance pulmonaire aiguë pendant une période de quatre ans (entre février et août 2011). Ils ont utilisé la régression logistique - où l'établissement était un effet aléatoire - pour examiner l'association entre les indicateurs présélectionnés et la mortalité ou l'intubation.

RÉSULTATS : Au total, 330 patients (moyenne [ \pm ÉT] de $30 \pm 12$ par centre) ont participé à l'étude. L'œdème pulmonaire (104 [31,5\%]) et la maladie pulmonaire obstructive chronique (99 [30,0\%]) étaient les principales indications pour initier la VNI. Les chercheurs ont remarqué des différences significatives entre les établissements dans les indications pour utiliser la VNI et ont consigné la spécialité du médecin ayant fait la réquisition et l'établissement où la VNI avait été effectuée. Même si les taux d'intubation n'étaient pas statistiquement significatifs entre les établissements (plage de $10,3 \%$ à $45,4 \%$ ), la mortalité variait considérablement (plage de $6,7 \%$ à $54,5 \% ; \mathrm{P}=0,006)$. Selon l'analyse multivariée, l'indicateur indépendant le plus significatif pour éviter l'intubation était une indication de « ne pas réanimer " (RC 0,11 [95\% IC 0,03 à 0,37]).

CONCLUSION : Il existe une importante variabilité dans l'utilisation de la VNI et les résultats cliniques s'y rapportant dans les centres canadiens de soins tertiaires. Une indication de " ne pas réanimer » prévenait l'intubation.

has increased internationally (6) within ICUs, emergency departments (EDs) $(7,8)$ and postanesthetic care units $(9)$, as well as medical wards and palliative care units $(10,11)$. However, the frequency of NIV use varies among sites and countries $(1,2,12-17)$, and may be underutilized in some diagnoses (18).

The quality of evidence supporting the use of NIV in various etiologies of acute respiratory failure varies. A recent Canadian clinical practice guideline (19) highlighted the varying strength of evidence to

${ }^{1}$ Department of Medicine, Kingston General Hospital, Queen's University, Kingston, Ontario; 2Department of Critical Care, Fraser Health and Division of Critical Care, University of British Columbia, Vancouver, British Columbia; ${ }^{3}$ Department of Critical Care Medicine, Sunnybrook Health Sciences Centre, and Interdepartmental Division of Critical Care Medicine, University of Toronto; ${ }^{4}$ Interdepartmental Division of Critical Care Medicine, the Keenan Research Centre and the Li Ka Shing Knowledge Institute, St. Michael's Hospital; ${ }^{5}$ Department of Medicine and Interdepartmental Division of Critical Care Medicine, Mount Sinai Hospital, University of Toronto, Toronto, Ontario;

${ }^{6}$ Department of Critical Care Medicine, Vancouver General Hospital, University of British Columbia, Vancouver, British Columbia; ${ }^{7}$ Division of Critical Care Medicine, Faculty of Medicine and Dentistry, University of Alberta, Edmonton, Alberta; ${ }^{8}$ Lawrence S Bloomberg Faculty of Nursing, University of Toronto, Toronto, Ontario; ${ }^{9}$ Division of Critical Care Medicine, University of British Columbia, Vancouver, British Columbia; ${ }^{10}$ Department of Critical Care Medicine, University of Calgary, Calgary; ${ }^{11}$ Division of Critical Care Medicine, University of Alberta, Edmonton, Alberta

Correspondence: Dr John Muscedere, Department of Medicine, Queens University, Kingston General Hospital, 76 Stuart Street, Kingston, Ontario K7L 2V7. Telephone 613-549-6666 ext 4642, e-mail muscedej@kgh.kari.net 
support the use of NIV. Firm guidelines could not be proposed for the use of NIV in the setting of community-acquired pneumonia, chest trauma and immunosuppressed patients.

We hypothesized that there is significant practice variation among Canadian institutions in NIV use for acute respiratory failure. To evaluate this hypothesis, we conducted a multicentre, prospective study of NIV utilization in Canadian acute care settings. The primary objective of the present study was to describe practice variation in NIV use among participating Canadian hospitals.

\section{METHODS}

An interdisciplinary group of Canadian clinicians (respiratory therapists, intensivists and a registered nurse) (see Appendix 1 for participating institutions) was assembled. In addition, a standardized data collection form was developed and a respiratory therapist champion was identified at each site. All adult ( $>16$ years of age) patients treated with NIV for acute respiratory failure of any etiology during a fourweek period at each hospital between February and August 2011 were included. Data were collected on patients located anywhere in the hospital: in the ED, ICU, coronary care unit (CCU ), high-acuity unit (HAU, including step-up or step-down units), ward (nonmonitored, defined as the lack of capacity for continuous electroencephalogram or oxygen saturation monitoring) or other. The timing of data collection periods varied among participating sites depending on local research ethics board approval processes and site capabilities. Approval was obtained from each local research ethics board; the need for informed consent was waived at each site.

The times and locations of NIV initiation and discontinuation were recorded. Also collected were data pertaining to patient characteristics, including age, sex, Glasgow Coma Scale (GCS) scores and arterial blood gas at the time of NIV initiation, goals of care (full code, do not resuscitate [DNR], no resuscitation in case of cardiac arrest, allowance for intubation), do not intubate [DNI], no intubation), indication for initiation of NIV (selected from a list of 17 indications), specialty of the physician ordering NIV (ED, ICU, respirology, other) and initial settings for NIV use. Patients were followed until NIV was discontinued and the reason for discontinuation was recorded (patient improvement, intubation or death), as well as survival status for the hospital admission. For patients with multiple NIV applications (ie, separate NIV initiations), only the index case was used in the analyses.

Data were entered into a central database REDCAP Version 3.3.0 (20) by a single research coordinator. All analyses were performed using SAS version 9.3 (SAS Institute Inc, USA). Categorical variables are reported as counts and percentages, while continuous variables are reported as means and SDs. Continuous and categorical variables were analyzed using the Mann-Whitney and Fisher's exact tests, respectively.

Practice variation in NIV utilization was explored among sites by comparing the most common indications for NIV use; specialty of ordering physician; location of NIV initiation and discontinuation; NIV modes, interfaces and settings used; overall clinical outcomes including rates of intubation and hospital survival; and intubation and survival rates in patients with DNR and DNI orders. Between-site variation of specific NIV practices and outcomes were assessed using Fisher's exact test. NIV modes, interfaces, settings and clinical outcomes specific to DNR/DNI orders were not formally tested due to insufficient sample size.

Logistic regression analysis, with site as a random effect, was used to examine independent associations between intubation or mortality (in two separate multivariate models) and selected predictors. The following predictors were selected a priori based on investigator opinion: age, sex, GCS, pH, code status, pulmonary edema, chronic obstructive pulmonary disease (COPD), pneumonia, postextubation respiratory failure, site and location of NIV initiation. Patients with a code status of DNI were excluded from the intubation logistic regression analysis and only patients for whom intubation was a possible outcome were included.

\section{RESULTS}

\section{Descriptive analysis}

Patient and institutional characteristics: Eleven tertiary care universityaffiliated centres participated in the study. Institutional characteristics are presented in Table 1. A total of 337 NIV initiations were recorded; five patients received treatment with NIV on two separate occasions, and one received NIV on three separate occasions, resulting in 330 unique patients for analysis, with a mean $( \pm S D)$ of $30.0 \pm 12.1$ patients per centre (range 11 to 51 patients per centre). In the remainder of the analyses, only the 330 index NIV initiations were included. Patient characteristics are presented in Table 2. Most patients had a GCS of 15 , while $21(6.4 \%)$ had a GCS $<10$ and nine $(2.7 \%)$ had a GCS $<8$. Resuscitation status was available for $319(96.7 \%)$ patients, of which 225 (68.2\%) were 'full code', 76 (23.0\%) were DNR and 18 (5.4\%) were DNI.

Indication for NIV initiation: Of the 330 unique patients, 271 (82.1\%) had a single indication for NIV initiation, $52(15.8 \%)$ had two indications (eg, COPD and pneumonia) and three (0.9\%) had three indications (eg, COPD, asthma and pulmonary edema). Pulmonary edema $(n=104[31.5 \%])$ and COPD $(n=99[30.0 \%])$ were the most common reasons for NIV initiation, followed by pneumonia ( $n=52$ [15.8\%]) and postextubation respiratory failure $(n=30$ [9.1\%]) (Figure 1). The least commonly selected reasons for NIV use $(\leq 6$ patients per category) included altered level of consciousness, asthma, chronic alveolar hypoventilation, pleural effusion, pulmonary fibrosis, weaning and neuromuscular weakness; these categories were subsequently collapsed into one category termed 'miscellaneous' to simplify data reporting. 'Other' was selected as the indication for NIV initiation for $23(7.0 \%)$ patients, and the reasons listed included: obesity, rib fractures, sepsis, possible obstructive sleep apnea or was not indicated.

Clinically relevant and statistically significant $(\mathrm{P}<0.001)$ differences in the indication for NIV use across participating sites were noted, with the proportion of patients receiving NIV at each site ranging from $16.3 \%$ to $54.2 \%$ for pulmonary edema, $9.1 \%$ to $56.0 \%$ for COPD, $8.0 \%$ to $32.6 \%$ for pneumonia and $0 \%$ to $20.8 \%$ for postextubation failure (Table 3).

Physicians ordering NIV and location of NIV administration: NIV was ordered most frequently by ED physicians (142 orders [43.0\%]), followed by ICU physicians (94 orders [28.5\%]) and respirologists (26 orders $[7.9 \%]$ ). The category 'other physician' (ie, not ED, ICU or respirology) was selected for 61 NIV orders (18.5\%) (Table 4). The most frequent location for NIV initiation and discontinuation was the ED (165 [50.0\%] and 117 [35.4\%], respectively). Initiation and discontinuation rates were $83(25.2 \%)$ and $28(8.5 \%)$, respectively, in the ICU, $22(6.7 \%)$ and 23 (7.0\%), respectively, in the CCU, 20 (6.1\%) and $26(7.9 \%)$, respectively, in HAUs, and $21(6.4 \%)$ and $26(7.9 \%)$, respectively, in nonmonitored wards (Table 4). There were missing data regarding location for 19 initiations $(5.8 \%)$ and 25 discontinuations (7.6\%). The differences in NIV initiation and discontinuation among locations represent transfers of care among units.

Significant variability $(\mathrm{P}<0.001)$ among sites was noted regarding the physician ordering NIV, with ED physicians ordering $9.1 \%$ to $62.5 \%$ of NIV initiations and respirologists ordering $0 \%$ to $25.6 \%$ of NIV initiations (Appendix 1). Also observed was significant variation $(\mathrm{P}<0.001)$ among sites in the location of NIV initiation with initiations on the wards ranging from $0 \%$ to $29.2 \%$ and, in HAUs, ranging from $0 \%$ to $25.5 \%$ (Appendix 1). Location of NIV discontinuation also varied significantly $(\mathrm{P}<0.001)$ according to site.

NIV modes, interfaces and humidification: Bilevel noninvasive positive pressure ventilation (including pressure support ventilation) was the most common mode (305 patients [92.4\%]) (Appendix 2). The mean expiratory positive airway pressure, positive end-expiratory pressure or continuous positive airway pressure was $8.6 \pm 11.8 \mathrm{cmH}_{2} \mathrm{O}$, while the mean inspiratory (pressure support; above expiratory positive airway pressure/ positive end-expiratory pressure) was $10.4 \pm 5.5 \mathrm{cmH}_{2} \mathrm{O}$. Most patients (321 [97.3\%]) used an oronasal or full-face interface (Appendix 3). Heated humidification was used for most patients (217 [65.8\%]), a heat 
TABLE 1

Institutional characteristics

\begin{tabular}{|c|c|c|c|c|c|c|}
\hline Site & Unique study patients & NIV events* & Total acute beds & Critical care beds & High acuity unit beds & Cardiac critical care beds \\
\hline A & 30 & 30 & 436 & 15 & 0 & 21 \\
\hline C & 29 & 29 & 358 & 16 & 10 & 9 \\
\hline E & 25 & 25 & 354 & 8 & 4 & 10 \\
\hline $\mathrm{F}$ & 43 & 44 & 860 & 24 & 38 & 10 \\
\hline G & 47 & 48 & 590 & 16 & 4 & 6 \\
\hline 1 & 11 & 14 & 438 & 16 & 8 & 6 \\
\hline J & 21 & 23 & 366 & 68 & 0 & 10 \\
\hline K & 51 & 51 & 402 & 23 & 22 & 14 \\
\hline Mean \pm SD & $30.0 \pm 12.1$ & $30.6 \pm 11.7$ & $506.9 \pm 218.4$ & $24.3 \pm 16.7$ & $13.2 \pm 13.6$ & $11 \pm 6.4$ \\
\hline
\end{tabular}

Data presented as $n$ unless otherwise specified. *Only index noninvasive ventilation (NIV) event is included in subsequent analysis

\section{TABLE 2}

\section{Patient characteristics}

\begin{tabular}{lc}
\hline Age, years $(n=327)$ & $69.9 \pm 14.6$ \\
Female sex $(n=326)$ & $150(45.4)$ \\
Glasgow Coma Scale score $(n=276)$ & $13.7 \pm 2.4^{*}$ \\
Code status $(n=319)$ & \\
Full code & $225(68.2)$ \\
Do not resuscitate & $76(23.0)$ \\
Do not intubate & $18(5.4)$ \\
Unknown & $11(3.3)$ \\
Baseline arterial blood gas & \\
$\mathrm{pH}^{(n=216)}$ & $7.3 \pm 0.1$ \\
$\mathrm{PaCO}_{2}(\mathrm{n}=216)$ & $59.3 \pm 26.0$ \\
$\mathrm{PaO}_{2}(\mathrm{n}=216)$ & $88.0 \pm 39.8$ \\
$\mathrm{HCO}_{3}(\mathrm{n}=209)$ & $27.5 \pm 7.7$ \\
\hline
\end{tabular}

Data presented as mean \pm SD or $n(\%)$. Only data for unique patients are presented $(n=330)$ as acquired at time of noninvasive ventilation initiation. ${ }^{*} 58.7 \%$ of patients had a Glasgow Coma Scale score of 15. $\mathrm{HCO}_{3}$ Bicarbonate; $\mathrm{PaCO}_{2}$ Partial pressure of carbon dioxide; $\mathrm{PaO}_{2}$ Partial pressure of oxygen

and moisture exchanger was used in only $14(4.2 \%)$ and no humidification for $93(28.2 \%)$ patients.

\section{Clinical outcomes}

Clinical outcomes according to site: Of the 328 patients for whom an intubation outcome was reported (310 of which were eligible for intubation based on code status), 69 (21.0\%) were intubated $(22.3 \%$ of patients eligible for intubation) (Figure 2). The number of patients who survived to hospital discharge was 239 (72.4\%), while 90 died (27.4\%); no data were available for one patient $(0.3 \%)$. Although intubation rates varied among sites from $10.3 \%$ to $45.5 \%$, the difference was not statistically significant $(\mathrm{P}=0.29)$. Mortality varied significantly among sites ( $\mathrm{P}=0.006$ ), ranging from $6.7 \%$ to $54.5 \%$ (Appendix 4 ).

Clinical outcomes according to indication for NIV initiation: Intubation rates according to indication for NIV were: $15.9 \%$ for pulmonary edema, $15.7 \%$ for COPD, $30.8 \%$ for pneumonia and $26.7 \%$ for postextubation respiratory failure. Mortality rates according to indication were: $21.7 \%$ for pulmonary edema, $17.1 \%$ for COPD, $38.5 \%$ for pneumonia and $30.0 \%$ for postextubation respiratory failure. However, indication for NIV was not a significant predictor of either intubation or mortality (Appendixes 5 and 6).

Clinical outcomes according to code status: Of 224 patients who were full code, 65 (29.0\%) were intubated and 41 (18.3\%) died. Of the patients who died, $18(43.9 \%)$ had been intubated. Of 76 patients who were DNR, three (3.9\%) were intubated and $36(47.4 \%)$ died. Of 18 patients who were DNI, none were intubated and 10 (55.6\%) died. Although all sites used NIV for DNR patients, only five sites used NIV

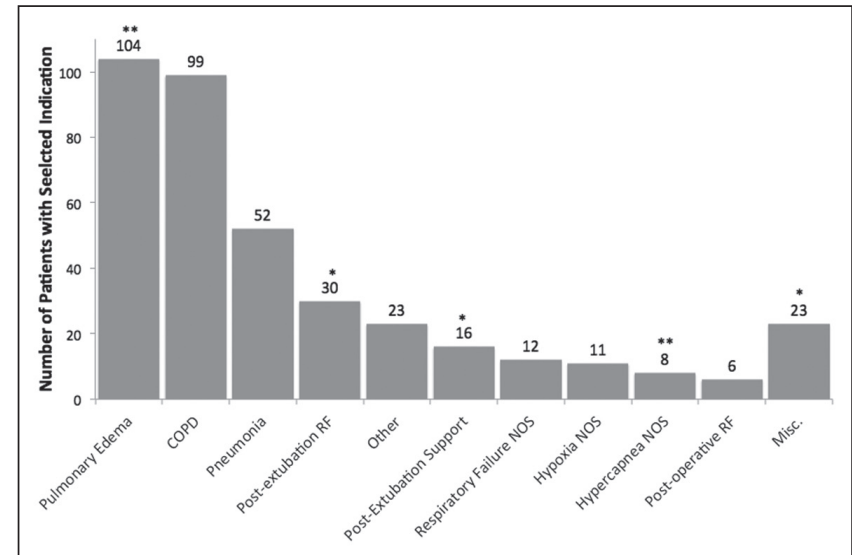

Figure 1) Although only index noninvasive ventilation (NIV) initiations are reported in the bar graph and corresponding counts, the total number of indications ( $n=384)$ is higher than the number of patients $(n=330)$ because some patients had multiple indications for their index NIV initiation. The asterisks denote the seven NIV re-initiations that have been excluded from the analysis. COPD Chronic obstructive pulmonary disease; Misc Miscellaneous (least commonly selected categories, including altered level of consciousness, asthma, chronic alveolar hypoventilation, pleural effusion, pulmonary fibrosis, weaning and neuromuscular weakness); NOS Not otherwise specified; Other Selected category by respiratory therapists with reasons listed including: obesity, rib fractures, sepsis, possible obstructive sleep apnea or was otherwise not indicated; RF Respiratory failure

for patients who were DNI. Outcomes for patients according to code status in are presented in Figure 3. NIV was used for palliation (ie, for comfort in a patient not expected to survive) in 18 (5.3\%) patients, five of whom survived to hospital discharge.

Predictors of intubation and mortality: In univariate analysis (Appendix 5), the patient characteristics that differed between intubated and nonintubated patients were age (older patients less likely to be intubated), GCS and DNR status. DNI patients were excluded because intubation was not a possible outcome for these patients and is confirmed by the fact that none of the DNI patients were intubated. In the multivariate model, the only independent predictor of intubation was DNR status. Patients with a DNR status were 0.11 (95\% CI 0.03 to 0.37 ) times as likely to be intubated compared with patients with full code status (Appendix 7).

Nonsurvivors tended to be older with lower GCS and were more likely to have: DNR/DNI status, pneumonia, respiratory failure 'not otherwise specified', and to have NIV initiated in the ICU, CCU or HAU (Appendix 6). In multivariate analysis DNR/DNI status and NIV initiation in the ICU, CCU or HAU were independent predictors 
TABLE 3

Variation in use by site according to indication

\begin{tabular}{lccccccccccc}
\hline Site & A & B & C & D & E & F & G & H & I & J & K \\
\hline Pulmonary edema & $12(40)$ & $10(41.7)$ & $11(37.9)$ & $13(52)$ & $8(32)$ & $7(16.3)$ & $11(23.4)$ & $13(54.2)$ & $3(27.2)$ & $5(23.8)$ & $11(21.6)$ \\
COPD & $9(30)$ & $3(12.5)$ & $7(24.1)$ & $7(28)$ & $14(56)$ & $21(48.8)$ & $15(31.9)$ & $8(33.3)$ & $1(9.1)$ & $3(14.3)$ & $11(21.6)$ \\
Pneumonia & $3(10)$ & $4(16.7)$ & $3(10.3)$ & $2(8)$ & $6(24)$ & $14(32.6)$ & $5(10.6)$ & $4(16.7)$ & $3(27.2)$ & $2(9.5)$ & $6(11.8)$ \\
Postextubation RF & $5(16.7)$ & $5(20.8)$ & $4(13.8)$ & $3(12)$ & $2(8)$ & $0(0)$ & $2(4.3)$ & $2(8.3)$ & $0(0)$ & $2(9.5)$ & $5(9.8)$ \\
\hline
\end{tabular}

Data presented as $n$ (\%), presented as percentage of patients with a given indication for NIV. The percentages may not add to $100 \%$ because only the four most common indications are presented and some patients may have more than one indication. The overall $P$ value comparing the distribution of indication by site using only the first indication per patient yielded a Fisher's exact test of $<0.001$. COPD Chronic obstructive pulmonary disease; RF Respiratory failure

TABLE 4

Physicians ordering noninvasive ventilation (NIV), and location of NIV initiation and discontinuation

\begin{tabular}{lcc}
\hline & Location & $\mathbf{n ~ ( \% )}$ \\
\hline Physician & Emergency department & $142(43)$ \\
& Intensive care unit & $94(28.5)$ \\
Respirology & $26(7.9)$ \\
Other & $61(18.5)$ \\
Location of NIV & No data & $7(2.1)$ \\
initiation & Emergency department & $165(50)$ \\
& Intensive care unit & $83(25.2)$ \\
Cardiac care unit & $22(6.7)$ \\
High acuity unit & $20(6.1)$ \\
Ward & $21(6.4)$ \\
Oocation of NIV & No data & $19(5.8)$ \\
discontinuation & Omergency department & $117(35.5)$ \\
& Intensive care unit & $91(27.6)$ \\
Cardiac care unit & $23(7)$ \\
High acuity unit & $28(8.5)$ \\
Ward & $26(7.9)$ \\
Other & $20(6.1)$ \\
No data & $25(7.6)$ \\
\hline
\end{tabular}

of mortality after adjusting for age, sex, $\mathrm{pH}$, GCS, pulmonary edema, COPD, pneumonia, post-extubation respiratory failure and site (Appendix 8).

\section{DISCUSSION}

In the present study, we found significant site variability among 11 Canadian tertiary care centres in indications for NIV, specialty of ordering physician, location of NIV initiation, level of pressure support at the time of NIV initiation and use of humidification.

\section{Use of NIV and associated outcomes}

There is strong evidence to support the use of NIV in COPD exacerbation $(3,21,22)$ and cardiogenic pulmonary edema $(3,22-25)$, and it has been suggested that NIV should be the first option for ventilatory support for patients with these diagnoses (19). In our study, COPD exacerbation and pulmonary edema were the two most common diagnoses for which NIV was initiated. We found that the use of NIV in patients with these indications was associated with relatively fewer intubations and lower mortality compared with other indications for NIV, though indication for NIV did not prove to be a significant variable in multivariate analysis. Rates of NIV failure requiring intubation or resulting in mortality were comparable to other reports (26). In particular, the higher rate of intubation in patients receiving NIV for respiratory failure secondary to pneumonia, compared with lower rates for pulmonary edema and COPD, is consistent with the lack of evidence in support of NIV use in this setting (19). The use of NIV for the indication of pneumonia, although not well supported by existing evidence, requires further investigation; possible reasons include lack

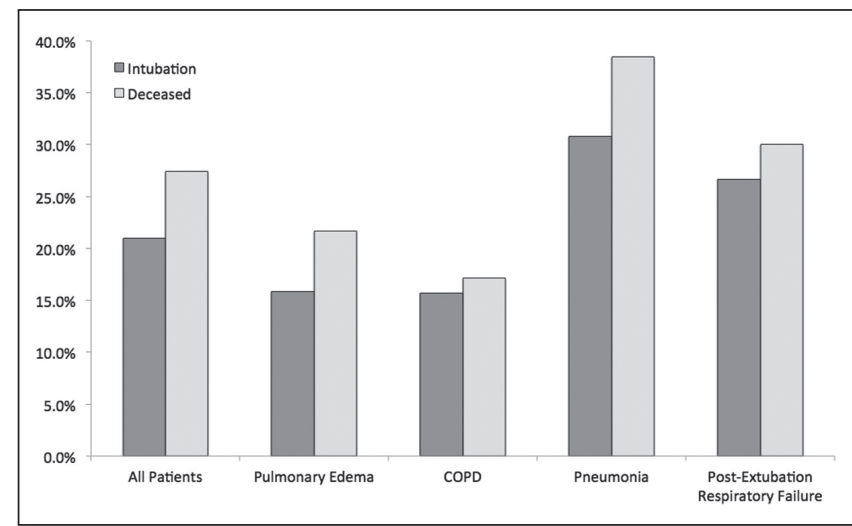

Figure 2) Clinical outcomes: intubation and mortality. COPD Chronic obstructive pulmonary disease

of awareness of evidence, coexisting COPD or pulmonary edema, or temporization while other investigations were performed or response to therapy was assessed.

Growing evidence supports the use of NIV to facilitate weaning and extubation in patients with hypercapneic acute respiratory failure $(27-29)$. There is also evidence for the use of NIV in improving respiratory outcomes postoperatively, including reduction in pulmonary morbidity, mortality, hypoxemia and length of stay (30-35), for allowing early liberation from the ventilator (36), and for avoiding reintubation following planned extubation $(37,38)$, although evidence for the latter is conflicting $(39,40)$. We found that postextubation respiratory failure, postextubation support (extubation directly to NIV) and postoperative respiratory failure together accounted for approximately $16 \%$ of all NIV initiations, although significant variability among sites was observed. We found that NIV was used for indications such as community-acquired pneumonia, asthma and pulmonary fibrosis, for which there is no evidence to support its use.

As the indications for NIV have expanded, it has become a means of providing respiratory support to patients who are not candidates for intubation (41). Approximately $30 \%$ of the patients in our study had a code status of DNR (23.6\%) or DNI $(5.8 \%)$. This varies from the $44 \%$ of patients with a DNR or DNI code status in an American study of NIV practices by Ozsancak Ugurlu et al (26), with the majority of the difference attributed to a greater proportion of DNI patients $(21.3 \%)$ in their study. Interestingly, in our study, fewer than one-half of the sites used NIV in patients that were DNI, indicating marked practice variation in use of NIV in patients with an alternative code status. Also of note was that only a very small percentage of DNR patients were intubated despite allowance for intubation with this code status. Finally, our finding that five of 18 patients for whom NIV was used for palliation survived to hospital discharge suggests that NIV may play a role in reversing respiratory failure in certain patients who are near the end of life.

Location of NIV initiation and prescribing physicians

NIV use has spread to areas outside of the ICU and is now more frequently seen in the $\operatorname{ED}(7,8)$ and postoperative recovery rooms $(9)$, as 
well as medical wards and palliative care units $(10,11)$. Our study confirms the common use of NIV outside of the ICU setting across Canadian centres. In fact, not only was the ED the most common location for NIV initiation, it was the location for one-half of all NIV initiations and over one-third of NIV discontinuations. Even so, this trend was not observed at all sites, because NIV initiation in the ED occurred in $<20 \%$ of cases at two sites. This variability was similarly observed in NIV prescribing practices of physicians across sites. While respirologists were less likely to be the initial prescriber of NIV in our study compared with a recent European survey (14), these differences can be attributed to organizational differences among regions, with respirologists in Europe less likely to work in ICUs and more likely to initiate NIV preventively on pulmonary wards and in different patient populations (14). Finally, HAU and wards represented the minority of sites for NIV use, and there was, once again, significant variability among sites. Together, these findings support the concept of a changing environment for NIV use with marked geographical variability $(9-11)$.

\section{NIV interfaces and settings}

Consistent with the findings from other recent studies, the most common interface used in Canadian centres was overwhelmingly an oronasal (full-face) mask (14) and the most common mode of NIV was bilevel positive airway pressure (pressure support ventilation) (26), with only a few sites choosing continuous positive airway pressure as an initial mode. However, clinically relevant variation existed in NIV settings, particularly in initial inspiratory pressure and humidification of air, recognizing that inspiratory pressure, in particular, is likely to be titrated according to patient response and final inspiratory pressure settings were not analyzed. Our finding of heated humidification or heat moisture exchanger use in $70 \%$ of patients is slightly higher than that of a recent European analysis finding use in approximately 55\% (14). These variations in practice among sites require further investigation and may, in part, be attributable to insufficient evidence to provide clear guidelines at this time (42).

\section{Strengths and limitations}

The present study had several strengths. Its multicentre and national scope enabled geographical comparisons in variability of NIV use that has not been previously demonstrated in Canada. The observational nature of the present study enabled it to proceed without patient consent, thereby minimizing inclusion bias. Furthermore, the prospective analysis of serial patients with no exclusion criteria, along with the use of a standardized data collection form, ensured that we collected data from a representative cohort. Finally, our well-defined a priori analyses ensure validity.

Our study had limitations. Notwithstanding the number of participating centres, the sample size is relatively small and limited to three provinces, with few patients per site. Because the present analysis was designed as a feasibility study, a four-week data collection period was arbitrarily chosen. However, data representing four weeks may not accurately represent local practices, and the variability in time of year studied (four weeks between February and August) may have led to perceived variation in frequency of presenting problems (eg, pneumonia) among centres. Although we found that mortality varied among centres, this should be interpreted cautiously because other factors, such as timing of data collection, severity of illness and small sample size, may account for this. We did not account for a measure of severity of illness in the model. Additionally, we only collected data from patients receiving NIV and, therefore, cannot comment on patients who were intubated without a trial of NIV. We are unable to assess whether there are patients who were not included in our data collection. Furthermore, there were multiple data collectors involved, and this may account for some of the variability in collected data. For example, it was common for more than one indication for NIV to be entered on the data collection form. Based on the number of 'other' diagnoses selected,

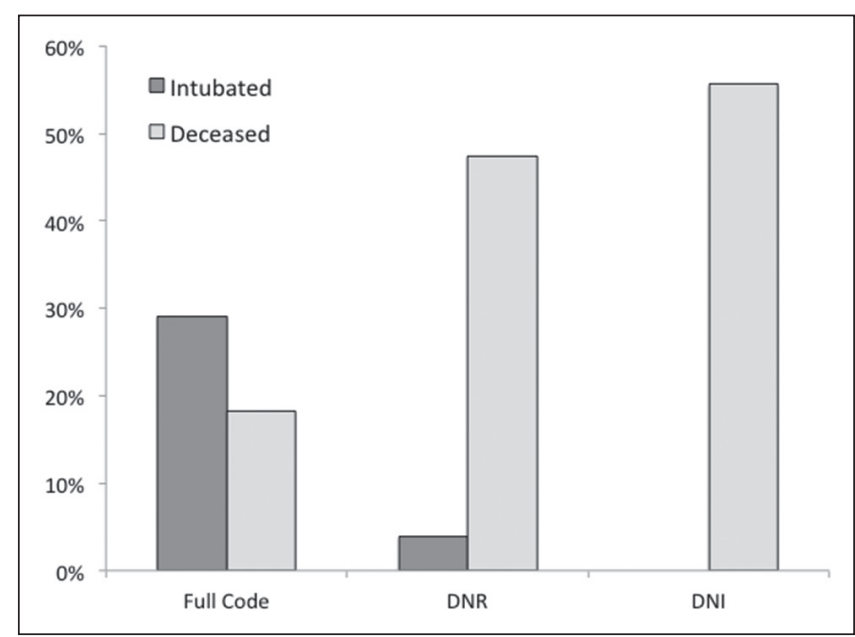

Figure 3) Clinical outcomes according to code status. DNR Do not resuscitate; DNI Do not intubate

the underlying diagnosis may not have always been clear to data collectors, and given that these were recorded at the time of NIV initiation, these may not reflect the final diagnosis.

In terms of generalizability of findings, our study involves a number of Canadian tertiary care academic centres from across the country; however, given recent data showing higher overall use of NIV in nonteaching hospitals (26), these results may not be representative of nonteaching hospitals and non-Canadian institutions. Furthermore, site comparison analysis may be affected by differing numbers of ICU beds and patients triaged, which was not taken into consideration and may limit generalizability of the data.

\section{CONCLUSIONS}

The present study demonstrates variability in NIV use among Canadian tertiary care centres. The reasons for this were not explored in the present study and may be due to a lack of knowledge of available evidence, lack of familiarity with existing clinical practice guidelines or a paucity of evidence in some diagnostic categories. Our findings need to be confirmed in a larger study with more diverse centres to explore reasons for variability. Further research is required to assess the impact of practice variation on outcomes and to guide quality improvement initiatives.

ACKNOWLEDGEMENTS: Author contributions: SK, CP, TS, KB, SM, JR, DK, LR, MA, LB, CD and DE made contributions to research design, acquisition of data from participating institutions and revising the paper critically. GD, SK and JM substantially contributed to data analysis and interpretation, drafting of the paper and preparing revised versions for submission. We would also like to acknowledge the following RTs and research coordinators who assisted in data collection: Elizabeth Rohrs and Jason Zurba (Royal Columbian Hospital), Kory Klashinsky (Surrey Memorial Hospital), Kerri Porretta (St Michael's Hospital), Sandi Ellis and Brooke Thompson (Sunnybrook), Vagia Campbell and John Traill (Mount Sinai Hospital), Jennifer Barchard (Grey Nuns Hospital), Derry Thibealut (Kingston General Hospital), Patricia Thompson (Royal Alexandra Hospital), Lynda Lazosky (St Paul's Hospital), Renee Sholes, Kristopher Jolin (Peter Lougheed/Foot Hills), and Corrie Irwin and Denis Foster (Vancouver General Hospital).

FUNDING: Funding included an unrestricted grant from Philips/ Respironics to support clinical practice guideline development with this study representing the first step toward a guideline implementation project to establish baseline utilization. Philips/Respironics had no role in the design or conduct of the study, nor in the interpretation of the results or preparation of the manuscript. 
APPENDIX 1

Physicians ordering and location of noninvasive ventilation (NIV) initiation and discontinuation according to site

\begin{tabular}{llcllllllllll}
\hline & & $\mathbf{A}$ & $\mathbf{B}$ & $\mathbf{C}$ & $\mathbf{D}$ & $\mathbf{E}$ & $\mathbf{F}$ & $\mathbf{G}$ & $\mathbf{H}$ & $\mathbf{I}$ & $\mathbf{J}$ & $\mathbf{K}$ \\
\hline Physician & ED & $15(50.0)$ & $8(33.3)$ & $9(31.0)$ & $11(44.0)$ & $15(60.0)$ & $18(41.9)$ & $26(55.3)$ & $15(62.5)$ & $1(9.1)$ & $3(14.3)$ & $22(43.1)$ \\
& ICU & $5(16.7)$ & $8(33.3)$ & $12(41.4)$ & $6(24.0)$ & $8(32.0)$ & $7(16.3)$ & $10(21.3)$ & $7(29.2)$ & $9(81.8)$ & $13(61.9)$ & $9(17.6)$ \\
& Resp & $0(0)$ & $1(4.2)$ & $1(3.4)$ & $3(12.0)$ & $0(0)$ & $11(25.6)$ & $8(17.0)$ & $0(0)$ & $0(0)$ & $1(4.8)$ & $1(2.0)$ \\
& Other & $10(33.3)$ & $7(29.2)$ & $7(24.1)$ & $5(20.0)$ & $1(4.0)$ & $6(14.0)$ & $2(4.3)$ & $2(8.3)$ & $1(9.1)$ & $4(19.0)$ & $16(31.4)$ \\
& No data & $0(0)$ & $0(0)$ & $0(0)$ & $0(0)$ & $1(4.0)$ & $1(2.3)$ & $1(2.1)$ & $0(0)$ & $0(0)$ & 0 & $3(5.9)$ \\
Location of NIV & ED & $16(53.3)$ & $8(33.3)$ & $12(41.4)$ & $14(56.0)$ & $16(64.0)$ & $24(55.8)$ & $27(57.4)$ & $18(75.0)$ & $1(9.1)$ & $3(14.3)$ & $26(51.0)$ \\
initiation & ICU & $4(13.3)$ & $5(20.8)$ & $8(27.6)$ & $5(20.0)$ & $8(32.0)$ & $15(34.9)$ & $8(17.0)$ & $3(12.5)$ & $9(81.8)$ & $13(61.9)$ & $5(9.8)$ \\
& CCU & $4(13.3)$ & $1(4.2)$ & $4(13.8)$ & $1(4.0)$ & $1(4.0)$ & $1(2.3)$ & $1(2.1)$ & $0(0)$ & $0(0)$ & $4(19.0)$ & $5(9.8)$ \\
& HAU & $0(0)$ & $2(8.3)$ & $0(0)$ & $2(8.0)$ & $0(0)$ & $0(0)$ & $1(2.1)$ & $2(8.3)$ & $0(0)$ & $0(0)$ & $13(25.5)$ \\
& Ward & $0(0)$ & $7(29.2)$ & $0(0)$ & $1(4.0)$ & $0(0)$ & $3(7.0)$ & $7(14.9)$ & $1(4.2)$ & $1(9.1)$ & $0(0)$ & $1(2.0)$ \\
& Other & $6(20.0)$ & $1(4.2)$ & $5(17.2)$ & $2(8.0)$ & $0(0)$ & $0(0)$ & $3(6.4)$ & $0(0)$ & $0(0)$ & $1(4.8)$ & $1(2.0)$ \\
Location of NIV & No data & $0(0)$ & $0(0)$ & $0(0)$ & $0(0)$ & $0(0)$ & $0(0)$ & $0(0)$ & $0(0)$ & $0(0)$ & $0(0)$ & $0(0)$ \\
discontinuation & ED & $10(33.3)$ & $4(16.7)$ & $7(24.1)$ & $12(48.0)$ & $14(56.0)$ & $18(41.9)$ & $22(46.8)$ & $13(54.2)$ & $0(0)$ & $3(14.3)$ & $14(27.5)$ \\
& ICU & $10(33.3)$ & $8(33.3)$ & $6(20.7)$ & $5(20.0)$ & $8(32.0)$ & $16(37.2)$ & $9(19.1)$ & $5(20.8)$ & $9(81.8)$ & $8(38.1)$ & $7(13.7)$ \\
& CCU & $4(13.3)$ & $0(0)$ & $5(17.2)$ & $1(4.0)$ & $1(4.0)$ & $2(4.7)$ & $1(2.1)$ & $1(4.2)$ & $0(0)$ & $1(9.1)$ & $7(13.7)$ \\
& HAU & $0(0)$ & $2(8.3)$ & $2(6.9)$ & $4(16.0)$ & $0(0)$ & $0(0)$ & $0(0)$ & $4(16.7)$ & $1(9.1)$ & $0(0)$ & $15(29.4)$ \\
& Ward & $0(0)$ & $5(20.8)$ & $1(3.4)$ & $1(4.0)$ & $0(0)$ & $7(16.3)$ & $6(12.8)$ & $0(0)$ & $0(0)$ & $0(0)$ & $6(11.8)$ \\
& Other & $6(20.0)$ & $1(4.2)$ & $3(10.3)$ & $2(8.0)$ & $2(8.0)$ & $0(0)$ & $5(10.6)$ & $0(0)$ & $0(0)$ & $1(4.8)$ & $0(0)$ \\
& No data & $0(0)$ & $4(16.7)$ & $5(17.2)$ & $0(0)$ & $0(0)$ & $0(0)$ & $4(8.5)$ & $1(4.2)$ & $1(9.1)$ & $8(38.1)$ & $2(4.0)$ \\
\hline
\end{tabular}

Data presented as $n(\%)$. The distribution of physician, location of initiation and location of discontinuation all differed significantly (all $P<0.001)$ according to site (Participating Institutions [in random order]: Grey Nuns Community Hospital, Edmonton, Alberta; Kingston General Hospital, Kingston, Ontario; Mount Sinai Hospital, Toronto, Ontario; Peter Lougheed Centre/ Foothills Medical Centre, Calgary, Alberta; Royal Alexandra Hospital, Edmonton Alberta; Royal Columbian Hospital, New Westminster, British Columbia; St. Michael's Hospital, Toronto, Ontario; St. Paul's Hospital, Vancouver, British Columbia; Sunnybrook Health Sciences Centre, Toronto, Ontario, Surrey Memorial Hospital, Surrey, British Columbia; Vancouver General Hospital, Vancouver, British Columbia. CCU Cardiac care unit; ED Emergency department; HAU High acuity unit; ICU Intensive care unit; Resp Respirology

\section{APPENDIX 2}

Noninvasive ventilation (NIV) nodes and settings per site

\begin{tabular}{|c|c|c|c|c|c|c|}
\hline \multirow[b]{2}{*}{ Site } & \multicolumn{3}{|c|}{ NIV modes, n (\%) } & \multicolumn{3}{|c|}{ NIV settings, mean \pm SD } \\
\hline & BiPAP & CPAP & Other/unknown & $\begin{array}{c}\text { Inspiratory pressure in } \mathrm{cmH}_{2} \mathrm{O} \\
\text { (above EPAP/PEEP) }\end{array}$ & EPAP/PEEP in $\mathrm{cmH}_{2} \mathrm{O}$ & Set rate \\
\hline $\bar{A}$ & $30(100)$ & 0 & 0 & $4.9 \pm 1.9$ & $8.3 \pm 2.0$ & $\mathrm{~N} / \mathrm{A}$ \\
\hline B & $23(95.8)$ & 0 & $1(4.2)$ & $10.4 \pm 3.9$ & $6.9 \pm 1.9$ & $5.4 \pm 5.8$ \\
\hline C & $29(100)$ & 0 & 0 & $10.4 \pm 5.3$ & $9.3 \pm 2.4$ & $4.7 \pm 3.8$ \\
\hline $\mathrm{D}$ & $25(100)$ & 0 & 0 & $14.6 \pm 10.3$ & $8.7 \pm 1.6$ & $6.7 \pm 12.8$ \\
\hline$E$ & $22(88.0)$ & $3(12.0)$ & 0 & $8.5 \pm 4.6$ & $8.3 \pm 2.1$ & $8.0 \pm 2.8$ \\
\hline $\mathrm{F}$ & $40(93.0)$ & $3(7.0)$ & 0 & $15.1 \pm 3.3$ & $8.8 \pm 1.9$ & $\mathrm{~N} / \mathrm{A}$ \\
\hline G & $46(97.9)$ & $1(2.1)$ & 0 & $7.7 \pm 3.0$ & $12.1 \pm 30.3$ & $7.2 \pm 6.8$ \\
\hline $\mathrm{H}$ & $22(91.7)$ & 0 & $2(8.3)$ & $13.8 \pm 2.1$ & $7.7 \pm 1.6$ & $6.2 \pm 1.7$ \\
\hline I & $11(100)$ & 0 & 0 & $9.8 \pm 4.2$ & $7.4 \pm 2.3$ & $4.0 \pm 0.0$ \\
\hline $\mathrm{J}$ & $18(85.7)$ & $1(4.8)$ & $2(9.5)$ & $10.6 \pm 4.5$ & $7.3 \pm 2.0$ & $12.8 \pm 4.3$ \\
\hline $\mathrm{K}$ & $39(76.5)$ & $11(21.6)$ & $1(2.0)$ & $8.9 \pm 3.9$ & $6.9 \pm 1.7$ & $10.8 \pm 2.5$ \\
\hline Total & $305(92.4)$ & $19(5.8)$ & $6(1.8)$ & $10.4 \pm 5.5$ & $8.6 \pm 11.8$ & $7.5 \pm 6.5$ \\
\hline
\end{tabular}

BiPAP Bilevel positive airway pressure; CPAP Continuous positive airway pressure; EPAP End-expiratory positive airway pressure; N/A Not available; PEEP Positive end-expiratory pressure; PSV Pressure support ventilation

\section{APPENDIX 3}

Noninvasive ventilation (NIV) interface and humidification according to site

\begin{tabular}{|c|c|c|c|c|c|c|c|}
\hline \multirow[b]{2}{*}{ Site } & \multicolumn{3}{|c|}{ NIV interface } & \multicolumn{4}{|c|}{ Humidification } \\
\hline & Oronasal/ full face & Nasal & Other/unknown & Heated & HME & None & Unknown \\
\hline B & $24(100)$ & 0 & 0 & $16(66.7)$ & $5(20.8)$ & $2(8.3)$ & $1(4.2)$ \\
\hline D & $25(100)$ & 0 & 0 & $3(12.0)$ & $1(4.0)$ & $21(84.0)$ & 0 \\
\hline$E$ & $25(100)$ & 0 & 0 & $14(56.0)$ & 0 & $9(36.0)$ & $2(8.0)$ \\
\hline $\mathrm{F}$ & $39(90.7)$ & $4(9.3)$ & 0 & $43(100)$ & 0 & 0 & 0 \\
\hline I & $11(100)$ & 0 & 0 & $10(90.1)$ & 0 & $1(9.1)$ & 0 \\
\hline J & $19(95.0)$ & 0 & $1(5.0)$ & $13(61.9)$ & $3(14.3)$ & $5(23.8)$ & 0 \\
\hline $\mathrm{K}$ & $49(96.1)$ & 0 & $2(3.9)$ & $37(72.5)$ & 0 & $12(23.5)$ & $2(3.9)$ \\
\hline Total & $321(97.3)$ & $4(1.2)$ & $5(1.5)$ & $217(65.8)$ & $14(4.2)$ & $93(28.2)$ & $6(1.8)$ \\
\hline
\end{tabular}

Data presented as $n$ (\%). HME Heat moisture exchanger 
APPENDIX 4

Clinical outcomes according to site

\begin{tabular}{lccccccccccc}
\hline & A & B & C & D & E & F & G & H & I & J & K \\
\hline Patients, $n$ & 30 & 24 & 29 & 25 & 25 & 43 & 47 & 24 & 11 & 21 & 51 \\
Intubated & $3(10.3)^{*}$ & $5(20.8)$ & $6(21.4)^{*}$ & $5(20.0)$ & $4(16.0)$ & $8(18.6)$ & $6(12.8)$ & $8(33.3)$ & $5(45.4)$ & $6(28.6)$ & $13(25.5)$ \\
Died & $2(6.7)$ & $5(20.8)$ & $11(37.9)$ & $7(28.0)$ & $6(24.0)$ & $8(18.6)$ & $8(17.4)^{*}$ & $10(41.7)$ & $6(54.5)$ & $6(28.6)$ & $21(41.2)$ \\
\hline
\end{tabular}

Data presented as $n(\%)$ unless otherwise indicated *Denotes missing information for a patient's mortality or intubation status and where percentage is calculated based on known outcomes

\section{APPENDIX 5}

\section{Univariate analysis for intubation}

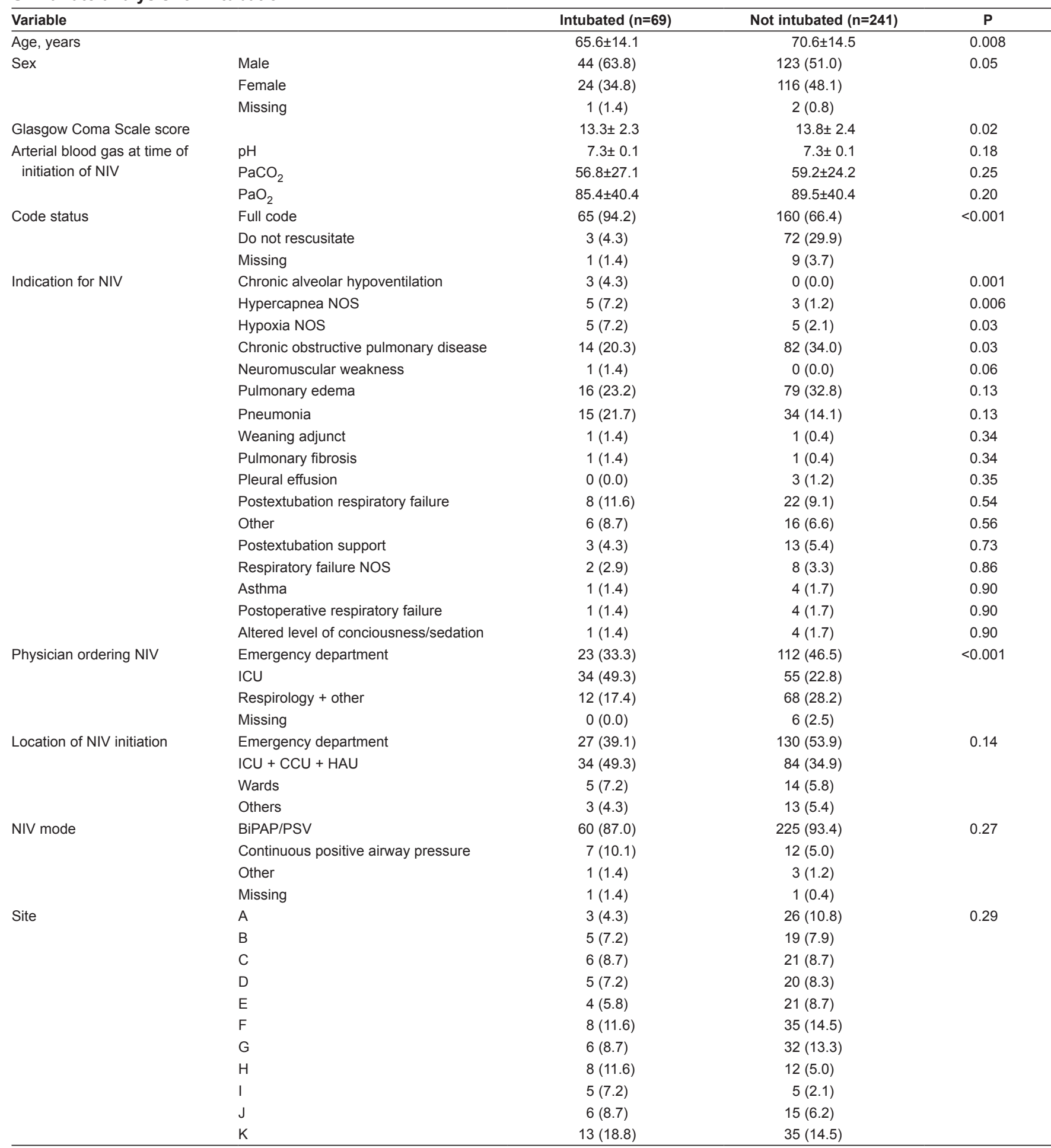

Data presented as $n(\%)$ or mean \pm SD. BiPAP Bilevel positive airway pressure; CCU Cardiac care unit; HAU High acuity unit; ICU Intensive care unit; NIV Noninvasive ventilation; NOS Not otherwise specified; $\mathrm{PaCO}_{2}$ Partial pressure of carbon dioxide; $\mathrm{PaO}_{2}$ Partial pressure of oxygen; PSV Pressure support ventilation 
Digby et al

APPENDIX 6

Univariate analysis for mortality

\begin{tabular}{|c|c|c|c|c|}
\hline Variable & & Alive $(n=239)$ & Deceased $(n=90)$ & $\mathbf{P}$ \\
\hline Age, years, mean \pm SD & & $68.4 \pm 14.6$ & $73.6 \pm 14.1$ & $<0.001$ \\
\hline \multirow[t]{2}{*}{ Sex } & Male & $129(54.0)$ & $46(51.1)$ & 0.62 \\
\hline & Female & $106(44.4)$ & $44(48.9)$ & \\
\hline $\begin{array}{l}\text { Glasgow Coma Scale score, } \\
\text { mean } \pm \text { SD }\end{array}$ & & $13.8 \pm 2.2$ & $13.3 \pm 2.7$ & 0.03 \\
\hline \multirow[t]{2}{*}{ Arterial blood gas, mean \pm SD } & $\mathrm{pH}$ & $7.3 \pm 0.1$ & $7.3 \pm 0.1$ & 0.30 \\
\hline & $\mathrm{PaO}_{2}$ & $89.4 \pm 42.2$ & $84.5 \pm 32.1$ & 0.58 \\
\hline \multirow[t]{4}{*}{ Code status } & Full code & $183(76.6)$ & $41(45.6)$ & $<0.001$ \\
\hline & Do not rescusitate & $40(16.7)$ & $36(40.0)$ & \\
\hline & Do not intubate & $8(3.3)$ & $10(11.1)$ & \\
\hline & Missing & $8(3.3)$ & $3(3.3)$ & \\
\hline \multirow[t]{11}{*}{ Indication for NIV } & Respiratory failure NOS & $5(2.1)$ & $7(7.8)$ & 0.02 \\
\hline & Pleural effusion & $2(0.8)$ & $2(2.2)$ & 0.30 \\
\hline & Asthma & $5(2.1)$ & $0(0.0)$ & 0.33 \\
\hline & Weaning adjunct & $1(0.4)$ & $1(1.1)$ & 0.47 \\
\hline & Pulmonary fibrosis & $1(0.4)$ & $1(1.1)$ & 0.47 \\
\hline & Hypoxia NOS & $7(2.9)$ & $4(4.4)$ & 0.50 \\
\hline & Pulmonary edema & $77(32.2)$ & $27(30.0)$ & 0.79 \\
\hline & Postextubation respiratory failure & $21(8.8)$ & $9(10.0)$ & 0.83 \\
\hline & Chronic alveolar hypoventilation & $2(0.8)$ & $1(1.1)$ & 1.00 \\
\hline & Postoperative respiratory failure & $5(2.1)$ & $1(1.1)$ & 1.00 \\
\hline & Postextubation support & $11(4.6)$ & $4(4.4)$ & 1.00 \\
\hline \multirow{2}{*}{ Location of NIV initiation } & Wards & $17(7.1)$ & $4(4.4)$ & \\
\hline & Other & $16(6.7)$ & $3(3.3)$ & \\
\hline \multirow[t]{4}{*}{ NIV mode } & BiPAP + PSV & $220(92.1)$ & $84(93.3)$ & 0.45 \\
\hline & Continuous positive airway pressure & $15(6.3)$ & $4(4.4)$ & \\
\hline & Other & $2(0.8)$ & $2(2.2)$ & \\
\hline & Missing & $2(0.8)$ & $0(0.0)$ & \\
\hline \multirow[t]{11}{*}{ Site } & A & $28(11.7)$ & $2(2.2)$ & 0.006 \\
\hline & B & $19(7.9)$ & $5(5.6)$ & \\
\hline & C & $18(7.5)$ & $11(12.2)$ & \\
\hline & $\mathrm{D}$ & $18(7.5)$ & $7(7.8)$ & \\
\hline & E & $19(7.9)$ & $6(6.7)$ & \\
\hline & $\mathrm{F}$ & $35(14.6)$ & $8(8.9)$ & \\
\hline & G & $38(15.9)$ & $8(8.9)$ & \\
\hline & $\mathrm{H}$ & $14(5.9)$ & $10(11.1)$ & \\
\hline & I & $5(2.1)$ & $6(6.7)$ & \\
\hline & $\mathrm{J}$ & $15(6.3)$ & $6(6.7)$ & \\
\hline & $\mathrm{K}$ & $30(12.6)$ & $21(23.3)$ & \\
\hline
\end{tabular}

Data presented as $n$ (\%) unless otherwise specified. BiPAP Bilevel positive airway pressure; CCU Cardiac care unit; ICU Intensive care unit; NIV Noninvasive ventilation; NOS Not otherwise specified; $\mathrm{PaCO}_{2}$ Partial pressure of carbon dioxide; $\mathrm{PaO}_{2}$ Partial pressure of oxygen; PSV Pressure support ventilation; Resp Respirology 


\section{APPENDIX 7}

\section{Multiple logistic regression analysis for intubation}

\begin{tabular}{lll}
\hline Selected predictor variables & \multicolumn{1}{c}{ OR $(95 \% \text { Cl })^{*}$} & P \\
\hline Age (per year) & $1.00(0.97$ to 1.02$)$ & 0.70 \\
Male & $0.57(0.31$ to 1.07$)$ & 0.08 \\
$\mathrm{pH}$ (per unit) & $2.60(0.08$ to 86.63$)$ & 0.59 \\
Glasgow Coma Scale score (per point) & $0.92(0.79$ to 1.07$)$ & 0.25 \\
Pulmonary edema & $0.62(0.29$ to 1.31$)$ & 0.21 \\
Chronic obstructive pulmonary disease & $0.50(0.23$ to 1.08$)$ & 0.08 \\
Pneumonia & $1.59(0.71$ to 3.57$)$ & 0.26 \\
Postextubation respiratory failure & $0.78(0.29$ to 2.07$)$ & 0.62 \\
DNR versus full code status & $0.11(0.03$ to 0.37$)$ & 0.0004 \\
NIV initiated in location other than ICU, & $0.64(0.33$ to 1.23$)$ & 0.18 \\
$\quad$ CCU or step-down/step-up & & \\
Remaining between-site variance ${ }^{\dagger}$ & ICC $=0.00^{\ddagger}$ & 0.67 \\
\hline
\end{tabular}

${ }^{*}$ An $O R>1$ indicated increased risk of intubation; ${ }^{\text {TT }}$ The $P$ value for betweensite variance was not estimated from the mixed logistic model, but rather from a Mantel-Haenszel test stratified according to quintiles for predicted probability of intubation as estimated by logistic regression considering all selected variables except site. The corresponding $P$ value for site without controlling for the other selected predictor variables was 0.20; \#Intraclass correlation coefficient (ICC) defined as proportion of logistic variance due to site after adjusting for covariates. CCU Cardiac care unit; DNR Do not resuscitate; ICU Intensive care unit; NIV Noninvasive ventilation

\section{REFERENCES}

1. Maheshwari V, Paioli D, Rothaar R, Hill NS. Utilization of noninvasive ventilation in acute care hospitals: A regional survey. Chest 2006;129:1226-33.

2. Butler V. Non-invasive ventilation (NIV). An audit across the North Central London Critical Care Network (NCLCCN). Intensive Crit Care Nurs 2005;21:243-56.

3. Nava S, Hill N. Non-invasive ventilation in acute respiratory failure. Lancet 2009;374:250-9.

4. Vitacca M, Ambrosino N, Clini E, et al. Physiological response to pressure support ventilation delivered before and after extubation in patients not capable of totally spontaneous autonomous breathing. Am J Respir Crit Care Med 2001;164:638-41.

5. Nava S, Ambrosino N, Clini E, et al. Noninvasive mechanical ventilation in the weaning of patients with respiratory failure due to chronic obstructive pulmonary disease. A randomized, controlled trial. Ann Intern Med 1998;128:721-8.

6. Esteban A, Ferguson ND, Meade MO, et al. Evolution of mechanical ventilation in response to clinical research. Am J Respir Crit Care Med 2008;177:170-7.

7. Bolton R, Bleetman A. Non-invasive ventilation and continuous positive pressure ventilation in emergency departments: Where are we now? Emerg Med J 2008;25:190-4.

8. Collins SP, Mielniczuk LM, Whittingham HA, Boseley ME, Schramm DR, Storrow AB. The use of noninvasive ventilation in emergency department patients with acute cardiogenic pulmonary edema: a systematic review. Ann Emerg Med 2006;48:260-9, 9 e1-e4.

9. Battisti A, Michotte JB, Tassaux D, van Gessel E, Jolliet P. Non-invasive ventilation in the recovery room for postoperative respiratory failure: A feasibility study. Swiss Med Wkly 2005; 135:339-43.

10. Cuomo A, Delmastro M, Ceriana P, et al. Noninvasive mechanical ventilation as a palliative treatment of acute respiratory failure in patients with end-stage solid cancer. Palliat Med 2004;18:602-10.

11. Principi T, Pantanetti S, Catani F, et al. Noninvasive continuous positive airway pressure delivered by helmet in hematological malignancy patients with hypoxemic acute respiratory failure. Intensive Care Med 2004;30:147-50.

12. Harris C, Saskin R, Burns KE. Noninvasive ventilation initiation in clinical practice: A six-year prospective, observational study. Can Respir J 2010;17:123-31.

13. Demoule A, Girou E, Richard JC, Taille S, Brochard L. Increased use of noninvasive ventilation in French intensive care units. Intensive Care Med 2006;32:1747-55.

\section{APPENDIX 8}

Multiple logistic regression analysis for mortality

\begin{tabular}{llc}
\hline Selected predictor variables & \multicolumn{1}{c}{ OR $(95 \%$ Cl $)$} & $\mathbf{P}$ \\
\hline Age (per year) & $1.02(0.99$ to 1.04$)$ & 0.16 \\
Male & $1.05(0.59$ to 1.89$)$ & 0.87 \\
pH (per unit) & $3.40(0.13$ to 91.33$)$ & 0.47 \\
Glasgow Coma Scale score (per point) & $0.90(0.78$ to 1.04$)$ & 0.17 \\
Pulmonary edema & $0.70(0.35$ to 1.41$)$ & 0.32 \\
Chronic obstructive pulmonary disease & $0.65(0.32$ to 1.33$)$ & 0.24 \\
Pneumonia & $1.56(0.73$ to 3.36$)$ & 0.25 \\
Postextubation respiratory failure & $0.89(0.32$ to 2.47$)$ & 0.82 \\
DNR or DNI versus full code status & $4.39(2.40$ to 8.00$)$ & $<0.0001$ \\
NIV initiated in location other than ICU, & $0.52(0.27$ to 0.98$)$ & 0.04 \\
$\quad$ CCU or HAU & & \\
Remaining between-site variance* & ICC $=0.08^{\dagger}$ & 0.12 \\
\hline
\end{tabular}

${ }^{*}$ The $P$ value for between-site variance was not estimated from the mixed logistic model, but rather from a Mantel-Haenszel test stratified in quintiles for predicted probability of mortality as estimated by logistic regression considering all selected variables except site. The corresponding $P$ value for site without controlling for the other selected predictor variables was 0.007 ; IIntraclass correlation coefficient (ICC) defined as proportion of logistic variance due to site after adjusting for covariates. An OR $>1$ indicates increased risk of mortality. CCU Cardiac care unit; DNR Do not resuscitate; DNI Do not intubate; HAU High acuity unit; ICU Intensive care unit; NIV Noninvasive ventilation

14. Crimi C, Noto A, Princi P, Esquinas A, Nava S. A European survey of noninvasive ventilation practices. Eur Respir J 2010;36:362-9.

15. Browning J, Atwood B, Gray A, group CPOt. Use of non-invasive ventilation in UK emergency departments. Emerg Med J 2006;23:920-1.

16. Burns KE, Sinuff T, Adhikari NK, et al. Bilevel noninvasive positive pressure ventilation for acute respiratory failure: Survey of Ontario practice. Crit Care Med 2005;33:1477-83.

17. Drummond J, Rowe B, Cheung L, Mayers I. The use of noninvasive mechanical ventilation for the treatment of acute exacerbations of chronic obstructive pulmonary disease in Canada. Can Respir J 2005;12:129-33.

18. Sweet DD, Naismith A, Keenan SP, Sinuff T, Dodek PM. Missed opportunities for noninvasive positive pressure ventilation: A utilization review. J Crit Care 2008;23:111-7.

19. Keenan SP, Sinuff T, Burns K, et al. Clinical practice guidelines for the use of noninvasive positive-pressure ventilation and noninvasive continuous positive airway pressure in the acute care setting. Can Med Assoc J 2011;183:e195-e214.

20. Harris PA, Taylor R, Thielke R, Payne J, Gonzalez N, Conde JG. Research electronic data capture (REDCap) - a metadata-driven methodology and workflow process for providing translational research informatics support. J Biomed Inform 2009;42:377-81.

21. Keenan SP, Sinuff T, Cook DJ, Hill NS. Which patients with acute exacerbation of chronic obstructive pulmonary disease benefit from noninvasive positive-pressure ventilation? A systematic review of the literature. Ann Intern Med 2003;138:861-70.

22. Lightowler JV, Wedzicha JA, Elliott MW, Ram FS. Non-invasive positive pressure ventilation to treat respiratory failure resulting from exacerbations of chronic obstructive pulmonary disease: Cochrane systematic review and meta-analysis. BMJ (Clinical research ed) 2003;326:185.

23. Vital FM, Ladeira MT, Atallah AN. Non-invasive positive pressure ventilation (CPAP or bilevel NPPV) for cardiogenic pulmonary oedema. The Cochrane database of systematic reviews 2013;5:Cd005351.

24. Masip J, Roque M, Sanchez B, Fernandez R, Subirana M, Exposito JA. Noninvasive ventilation in acute cardiogenic pulmonary edema: Systematic review and meta-analysis. JAMA 2005;294:3124-30.

25. Peter JV, Moran JL, Phillips-Hughes J, Graham P, Bersten AD. Effect of non-invasive positive pressure ventilation (NIPPV) on mortality in patients with acute cardiogenic pulmonary oedema: A meta-analysis. The Lancet 2006;367:1155-63. 
26. Ozsancak Ugurlu A, Sidhom SS, Khodabandeh A, et al. Use and outcomes of noninvasive positive pressure ventilation in acute care hospitals in Massachusetts. Chest 2014;145:964-71.

27. Ferreyra G, Fanelli V, Del Sorbo L, Ranieri VM. Are guidelines for non-invasive ventilation during weaning still valid? Minerva Anest 2011;77:921-6.

28. Ferrer M, Esquinas A, Arancibia F, et al. Noninvasive ventilation during persistent weaning failure: a randomized controlled trial. Am J Respir Crit Care Med 2003;168:70-6.

29. Burns KEA PA, Meade MO, Adhikari NKJ. Weaning critically ill adults with noninvasive positive pressure ventilation: An Updated Systematic Review and Meta-Analysis. Can Med Assoc J 2014;186:e112-e122.

30. Pelosi $\mathrm{P}$, Jaber $\mathrm{S}$. Noninvasive respiratory support in the perioperative period. Curr Opin Anaesthesiol 2010;23:233-8.

31. Bohner H, Kindgen-Milles D, Grust A, et al. Prophylactic nasal continuous positive airway pressure after major vascular surgery: Results of a prospective randomized trial. Langenbeck's archives of surgery / Deutsche Gesellschaft fur Chirurgie 2002;387:21-6.

32. Fagevik Olsen M, Wennberg E, Johnsson E, Josefson K, Lonroth H, Lundell L. Randomized clinical study of the prevention of pulmonary complications after thoracoabdominal resection by two different breathing techniques. Br J Surg 2002;89:1228-34.

33. Kindgen-Milles D, Muller E, Buhl R, et al. Nasal-continuous positive airway pressure reduces pulmonary morbidity and length of hospital stay following thoracoabdominal aortic surgery. Chest 2005;128:821-8.
34. Squadrone V, Coha M, Cerutti E, et al. Continuous positive airway pressure for treatment of postoperative hypoxemia: A randomized controlled trial. JAMA 2005;293:589-95.

35. Auriant I, Jallot A, Herve P, et al. Noninvasive ventilation reduces mortality in acute respiratory failure following lung resection. Am J Respir Crit Care Med 2001;164:1231-5.

36. Burns KE, Adhikari NK, Keenan SP, Meade M. Use of non-invasive ventilation to wean critically ill adults off invasive ventilation: Meta-analysis and systematic review. BMJ (Clinical research ed) 2009;338:b1574.

37. Ferrer M, Valencia M, Nicolas JM, Bernadich O, Badia JR, Torres A. Early noninvasive ventilation averts extubation failure in patients at risk: A randomized trial. Am J Respir Crit Care Med 2006;173:164-70.

38. Nava S, Navalesi P, Conti G. Time of non-invasive ventilation. Intensive Care Med 2006;32:361-70.

39. Keenan SP, Powers C, McCormack DG, Block G. Noninvasive positive-pressure ventilation for postextubation respiratory distress: A randomized controlled trial. JAMA 2002;287:3238-44.

40. Esteban A, Frutos-Vivar F, Ferguson ND, et al. Noninvasive positive-pressure ventilation for respiratory failure after extubation. N Engl J Med 2004;350:2452-60.

41. Sinuff T, Cook DJ, Keenan SP, et al. Noninvasive ventilation for acute respiratory failure near the end of life. Critical Care Med 2008;36:789-94.

42. Branson RD, Gentile MA. Is humidification always necessary during noninvasive ventilation in the hospital? Respir Care 2010;55:209-16; discussion 16. 


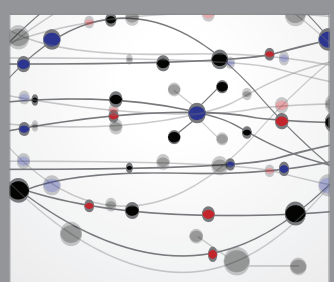

The Scientific World Journal
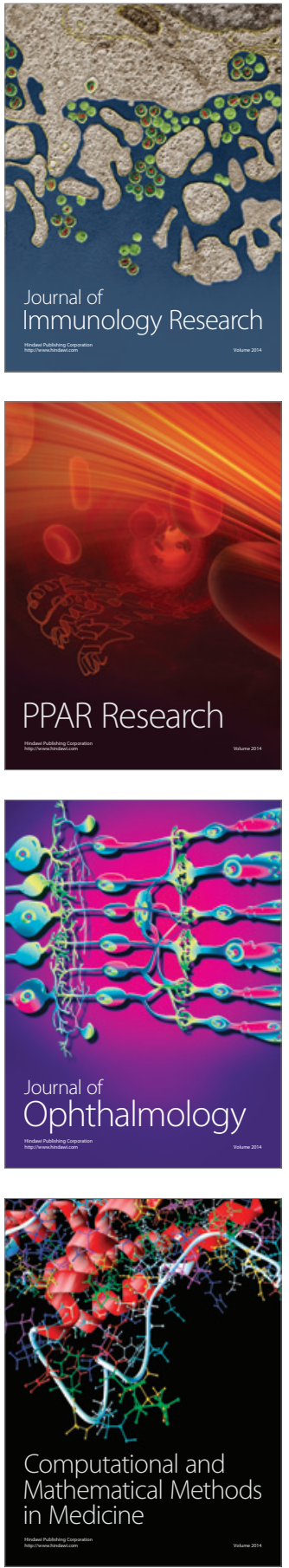

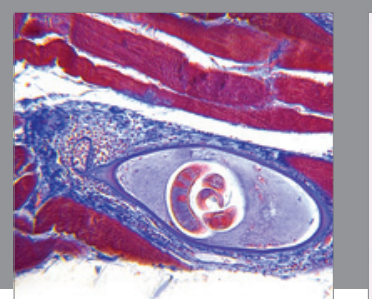

Gastroenterology Research and Practice

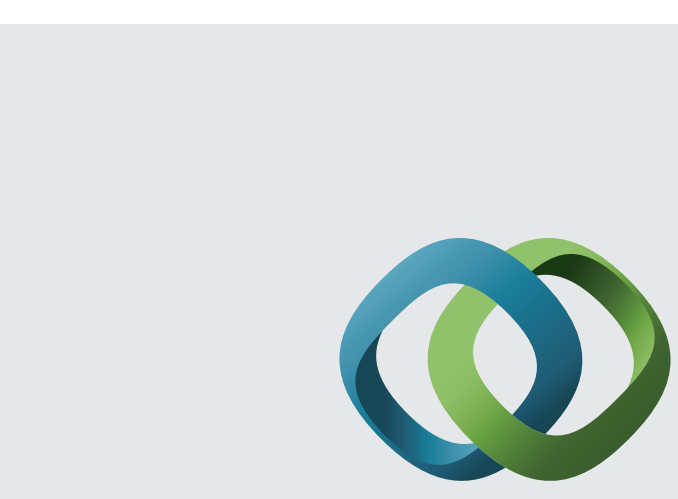

\section{Hindawi}

Submit your manuscripts at

http://www.hindawi.com
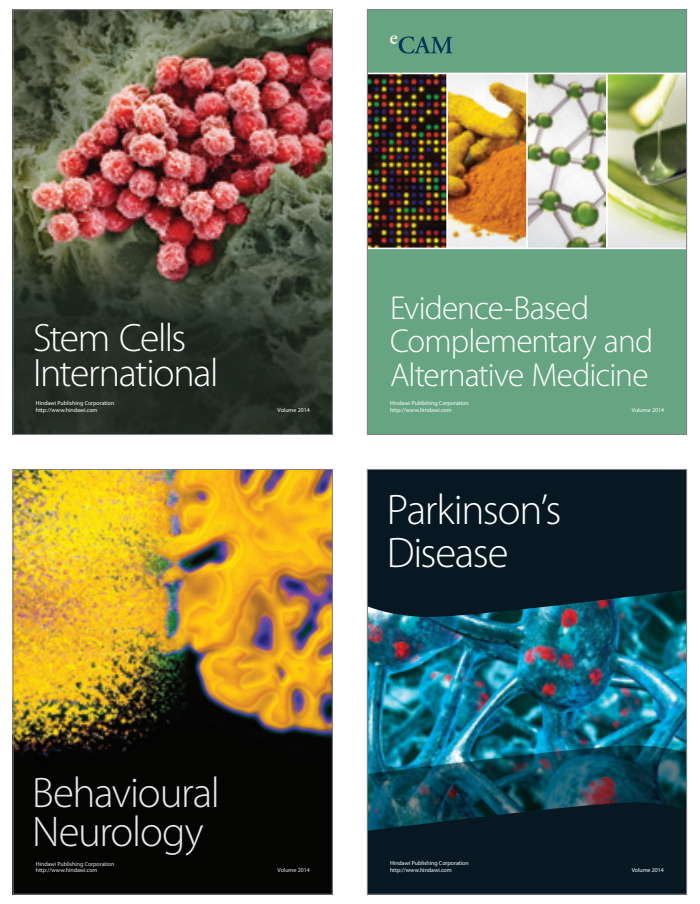
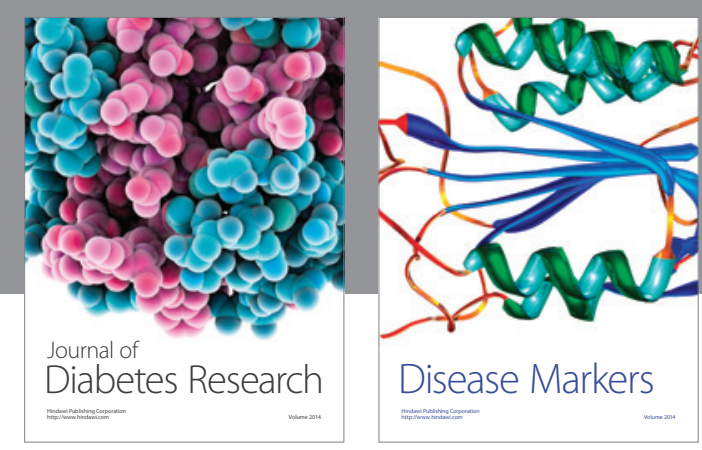

Disease Markers
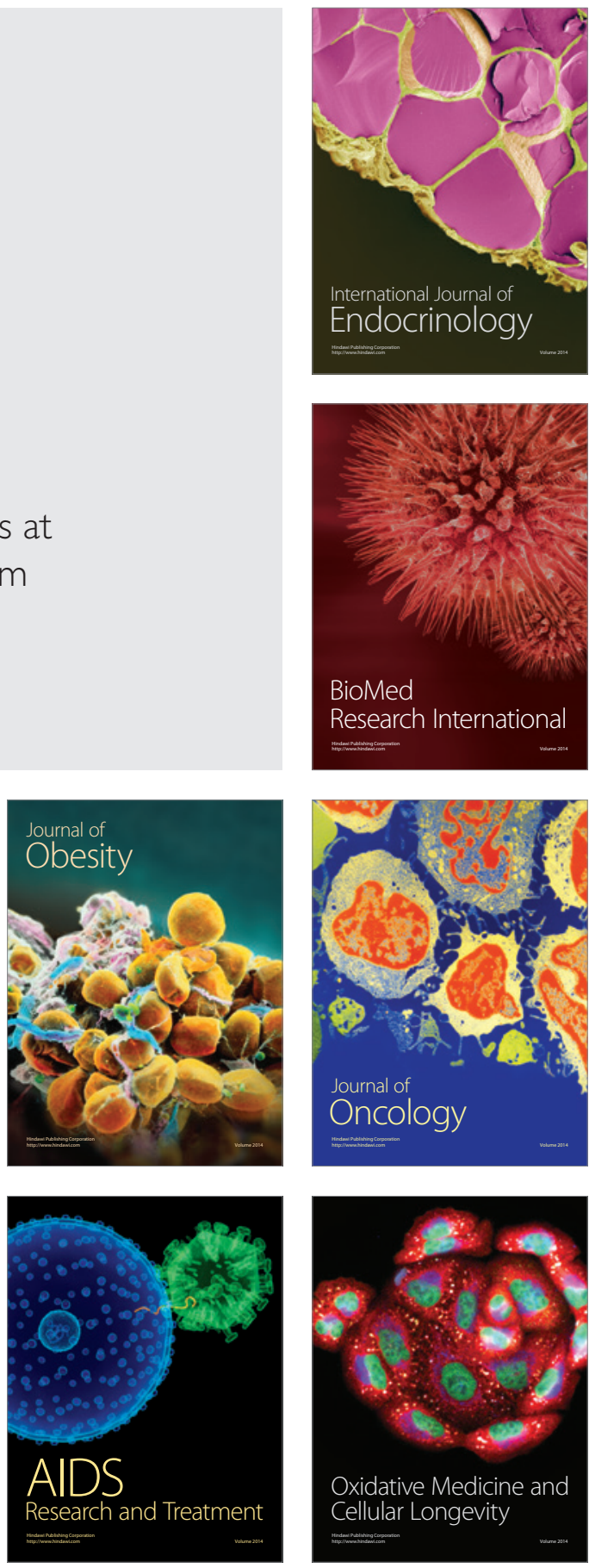